\title{
IS SCANDINAVIAN INFORMATION SYSTEMS DEVELOPMENT BECOMING PASSÉ?
}

\author{
Juhani Iivari
}

Department of Information Processing Science, University of Oulu, 90014 Oulun yliopisto, Finland; Juhani.iivari@oulu.fi

\begin{abstract}
This essay discusses possible intellectual contributions of the Scandinavian IS research traditions to the future of IS as a discipline. It suggests that the infological problems identified by Langefors still capture much of the essence of IS as a discipline of computing. The essay also revisits the infological equation, showing its continued relevance in the field. Finally, it discusses some trends in ISD.
\end{abstract}

Key words: Organizational alignment, user requirement, knowledge, information, data

\section{INTRODUCTION}

In their historical review of the "Scandinavian approach" (or more strictly the Nordic approach) to information systems development (ISD), Iivari and Lyytinen (1998) did not attempt to define the "Scandinavian approach" but pointed out that it is a plurality of approaches rather than a monolithic unit. These approaches differ substantially in their explicit or implicit value orientation, distinctive constructs used to clarify the concepts of IS and ISD, and the focus on ISD in terms of process coverage, stakeholders and type of system. Despite these differences, we can regard them as 'Scandinavian' due to their geographical or genealogical origin and due to their orientation. The Scandinavian approaches as whole have the characterization of "grass root" approaches as compared with the North American MIS tradition. They have emphasized IS evolution, user partici- 
pation, alternative process models and the seeking of varying theoretical foundations for IS and ISD.

More specifically, Iivari and Lyytinen (1998) analysed ten Scandinavian ISD approaches, Infological, Formal, Socio-Technical, Sociocybernetic, Trade Unionist, Language Action, Professional Work Practice, ObjectOriented, Activity Theory and the Structuration Theory, pointing out that the Scandinavian approaches as whole have made a substantial intellectual contribution to information systems as a discipline, whereas the practical contribution is more questionable.

The purpose of this essay is not to update their analysis but to take a personal look at the future of the Scandinavian approaches in view of the likely evolution of IS as a discipline. First, one may question whether there is space for distinctively Scandinavian approaches in the increasingly globalized world partly made possible by information technology. Among the Scandinavian approaches reviewed in Iivari and Lyytinen (1998), the Trade Unionist approach of the 1970's and 1980's is the best example of a distinctively Scandinavian contribution based on the strong trade unions characteristic of the Scandinavian societies (Spinuzzi, 2002). It seems, however, that distinctively Scandinavian approaches to ISD are fading out.

Thus, instead of looking for distinctively Scandinavian approaches, this essay will attempt to assess possible intellectual contributions of the Scandinavian IS research traditions in the foreseeable future. It is structured in terms of three revisits. First, it revisits the infological problems (Langefors, 1977) and demonstrates their continued relevance, suggesting that they largely capture the distinctive ISD competences of IS experts. This brings a normative aspect into the essay: the author's view of areas in which Scandinavian and non-Scandinavian IS researchers should especially invest their efforts. Second, the essay revisits the infological equation (Langefors, $1966 ; 1980)$ and illustrates its continued validity as a succinct crystallization of the relationship between data, information and knowledge, interest in which has been revived recently, especially in Knowledge Management (KM). Finally, the essay revisits the ISD process and takes up a couple of recurrent trends in it: the increased use of pre-fabricated software in ISD and the move towards light methods.

\section{INFOLOGICAL PROBLEMS REVISITED}

\subsection{Background}

Langefors (1977) makes a distinction between the infological problem of specifying the service provided and the datalogical problem of designing and 
realizing the data system that provides the specified service. He further divides the infological problem into three parts:

- Object system analysis and design (organizational change)

- Information analysis and design (user concepts and work)

- Implementation of the new (organizational) system

The application areas of information systems in the 1970's were largely limited to operative and managerial systems. Table 1 shows, however, that the more recent application areas include the same infological problems of understanding the activities to be supported by the information system, specifying the information services provided by the information system, while at the same time taking into consideration the technical possibilities, and the organizational implementability of the system. Table 1 also shows that there are plenty of infological research problems involved with the understanding that information systems support these activities with appropriate information services to support those activities. This is obvious in the context of the more recent application areas, but applies even in the case of operative information systems (e.g. ERP) and managerial information systems. To exemplify the latter, much of the research into Decision Support Systems (DSS) is based on Simon's (1960) model of decision making (intelligence, design, choice), whereas Langley et al. (1995) proposed five alternative models, which to my knowledge have been seriously neglected in DSS research.

As far as the more recent systems/technologies such as Content Management Systems (CMS) and Knowledge Management Systems (KMS) are concerned, Smith and McKeen (2003) point out that no one really knows what Content Management is. It is obvious, however, that if Content Management is not to be used only as a fashionable buzzword, one must pay serious attention to the "content" included in CMSs. ${ }^{\text {" Knowledge }}$ Management Systems (KMS) encounter similar problems of what are the services (expertise and knowledge) that make them in some sense distinctive. Content Management Systems and Knowledge Management Systems illustrate another infological problem. Neither of them is based on clear ideas of the activities to be automated and/or supported.

Table 1: Infological problems in selected application areas

1 The word "content" has a number of meanings, of which the following, as quoted in the Oxford English Dictionary (second edition 1989) seem most relevant in this context: 2.a. spec. ( $p l$.) The things contained or treated of in a writing or document; the various subdivisions of its subject-matter, 2.b. table of contents (content): a summary of the matters contained in a book, in the order in which they occur, usually placed at the beginning of the book, 3.a. The sum or substance of what is contained in a document; tenor, purport, 4 . The sum of qualities, notions, ideal elements given in or composing a conception; the substance or matter (of cognition, or art, etc.) as opposed to the form. 


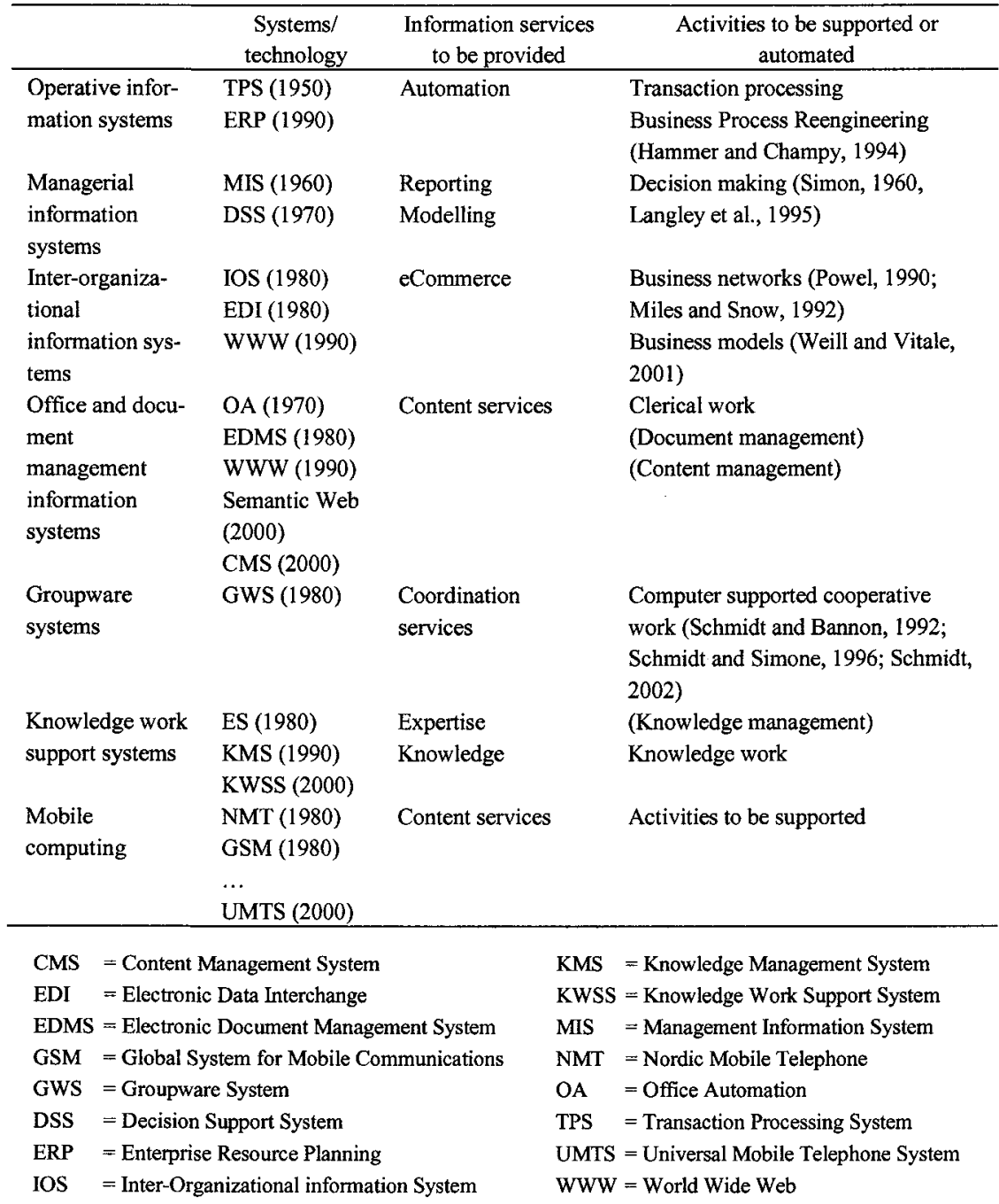

Content Management and Knowledge Management do not really specify the users or the activities in which the content, expertise, and knowledge services provided by CMSs and KMSs are really used. In the context of KMSs, I would suggest that it is more appropriate to talk about Knowledge Work Support Systems (KWSS). By knowledge work, I refer to work with four characteristics (Iivari and Linger, 1999): (i) it is based on a body of knowledge (BoK), (ii) it entails working on representations (data) of the objects of the work, (iii) it stipulates a deep, theoretical understanding of the 
objects of work, and (iv) its results entail knowledge as an essential ingredient.

The three infological problems identified by Langefors (1977) correspond closely to the IS experts' distinctive competence areas of information/software systems development proposed by livari et al. (2001):

- Organizational alignment

- User requirements construction

- Organizational implementation

- IS evaluation/assessment

Organizational alignment refers to the process in which the information system is aligned with the organizational and social context into which it is embedded. User requirements construction points to defining the information services to be provided by the system in order to satisfy the needs of its users. ${ }^{2}$ Organizational implementation refers to the institutionalization of the information system in its organizational and social context. By contrast, with the software engineering tradition, it is significant to make a distinction between organizational alignment and requirements construction. One reason is the dilemma between the organizational change and users' capabilities to express their requirements. Normally full deployment of the potential of IT requires changes in organizational work practices. The more the new work practices differ from the current ones, however, the harder it is for users the figure out the requirements for the new system.

I shall discuss the first two infological problems (competence areas) in more detail in the following, especially from the perspective of Scandinavian IS research. One reason for this is that the Scandinavian contribution to the latter two areas seems to be very limited. With respect to the problem of organizational implementation, it seems that the Scandinavians have been much more interested in the design of systems than in their organizational implementation and acceptance. There is an extensive worldwide literature on IS evaluation, especially concerning user information satisfaction, but much of this research is not clearly integrated into ISD development. ${ }^{3}$

2 The term "requirements construction" was originally coined by Flynn (1996). Like "requirements engineering", it implies that requirements are not out there to be gathered and analyzed but are socially constructed. I prefer "requirements construction" because it does not imply a specific engineering paradigm.

3 To my knowledge, the PSC method (Kerola and Järvinen, 1975) and the PIOCO method (Iivari and Koskela, 1979; 1987) as its successor were the first to include IS evaluation and related quality and choice criteria as integral parts of an ISD method. 


\subsection{Organizational alignment of information systems}

Langefors (1977) saw that an information system and its organizational context can be aligned by conscious object system analysis and design. For a number of reasons, this process has become more of a reciprocal, continuing process of aligning the information system and its organizational context rather than a one-time decision. Organizations have changed from formal-rational structures towards more interactionist forms (cf. Kling and Scacchi, 1980; Kling and Scacchi, 1982), technology has become more flexible, and the relationship between the technology and its organizational context has become socially more complex (Iivari and Hirschheim, 1996). As a result, it is neither possible nor necessary to the same extent as earlier to align the information system and its organizational context by deliberate design. It can be more an evolutionary process in which the technology and the organizational context are gradually aligned with each other. In fact, the process may also be an emergent one in the sense that there is no final "alignment."

There is a rich body of IS literature that addresses the issue of making an information system 'fit' (Iivari, 1992) its organizational and social context. Most of this pervious research has been limited to the initial design and implementation of the system, however, without paying attention to the postimplementation mutual adaptation of the system, its use, and the organizational context. Barley's (1986) study of the adopting of CR scanners in two radiological departments and the case study of Majchrzak et al. (2000) describing the dynamics of adopting groupware technology in a virtual team nicely illustrate the dynamics of the alignment process. In view of this neglect, it is not so surprising that Scandinavian IS research has not contributed much to the dynamic process of aligning the information system with its organizational context, although the dissertations of Karsten (2000) and Porra (1996) at least partly address the problem. Karsten's dissertation, like Barley's work, reflects theoretically Gidden's (1984) structuration theory, which seems to provide a useful theoretical lens for viewing this dynamic process. Porra's (1996) dissertation builds on biological colonial systems and evolution in these.

Based on their review of all articles published in the Scandinavian Journal of Information Systems up to 1997, Henfridsson et al. (1997) concluded that Scandinavian IS research has largely neglected organization theory as a reference discipline. This neglect may be explained by the predominance of the Trade Unionist approach in Scandinavian ISD discourse from the late 1980's onwards. After its first phase, informed by

4 There is a similarity here, of course, to the distinction between deliberate strategy and emergent strategy (Minzberg, 1994). 
the class theory view of organizations (Kling and Scacchi, 1980), the Trade Unionist approach adopted a view that the essence of work is tacit (Ehn, 1988). Consequently, it did not pay attention to the articulation of the work supported by information systems but instead adopted a strategy of "computer artifact-oriented design work" rather than "work-oriented design of computer artifacts" (Ehn, 1988). One could interpret this artifact-oriented design of work, using cooperative prototyping for example, as emphasizing the evolutionary process of aligning the information system and its organizational context, but I am not aware of any studies of the postimplementation mutual adaptation of the system and its organizational context.

More recently, the Activity Theory-based approach and the Structuration Theory-based approach have attempted to fill the above void. Kuutti (1990), for example, suggested the concept of activity as an intermediate between individual actions and a larger social system (such as an organization). Activity theory also has the benefit that it does not reflect organizational or inter-organizational contexts of activity, but may also cover any activities in families and society (which we do not normally regard as organizations). On the other hand, at least activity theorists in the IS field have had a tendency to neglect organization theory as a reference discipline, despite the fact that the activities often take place in an organizational context. ${ }^{5}$

\subsection{User requirements construction}

Despite all the progress made in its methods and techniques, requirements construction (engineering) still continues to be the major problem in information systems and software development. There are a number of explanations for this. Information systems and software products have become more complex and their information requirements more fuzzy (Iivari and Kerola, 1983) in the sense that it is not possible to define absolutely correct (complete and consistent) requirements. One further reason is that methods and techniques for requirements construction are developed without paying proper attention to the nature of the requirements. This has biased the methods and techniques to focus on limited types of requirements.

Iivari and Hirschheim (1996) identify three views of user requirements: objective, subjective and intersubjective. ${ }^{6}$ The objective view emphasizes

5 A review of recent papers in the special issues of Scandinavian Journal of Information Systems (Vol. 12, 2000) and Computer Supported Cooperative Work (Vol. 11, Nos. 1-2, 2002) on Activity Theory clearly confirms this.

6 The three views of user requirements bear some similarity to the "agreement" dimension in the three-dimensional framework for requirements engineering proposed by Pohl 
the importance of impersonal features such as the organizational position and task of the user as a determinant of his/her information requirements or the objective existence of the slice of reality modeled by the system. The subjective view stresses that the personal characteristics of the user (his frame of reference, cognitive styles, etc.) primarily determine the information requirements. The intersubjective view emphasizes the need to attain intersubjectivity among the community of IS users so that the system can serve their communication needs. Information requirements are socially negotiated and are a matter of social agreement.

The Scandinavian contribution in the area of objectivist requirements construction has been substantial. The infological tradition, especially the ISAC method (Lundeberg et al., 1978; 1981), includes the idea that requirements can be derived from a detailed analysis of users' work (activity studies). Many later methods, of which Contextual Design (1998) is a recent example, have followed this lead. To my knowledge, Bubenko (1980) was the first to propose the idea that requirements could derived from the theory of the application domain (Gustafsson et al., 1982). The Trade Unionist approach is not very explicit in its view of user requirements. User participation, mock-ups, and prototyping may in principle support objectivist, subjectivist, and intersubjectivist views of user requirements. Nevertheless, my general impression is that the Trade Unionist approach places its major emphasis on the objective, although essentially tacit, requirements of work. More recent methods and techniques of requirements construction based on use cases (Jacobson et al., 1992; Booch et al., 1999) and related scenarios mainly reflect the objective view of user requirements.

The subjective view of information requirements genuinely reflects a user-centered approach. ${ }^{7}$ Research into DSS has paid most attention to subjective user requirements, but otherwise the subjective view has been largely neglected in research into user requirements. The idea of personification, however (Brusilovsky, 1996), is a new attempt to take users as individual personalities into account in IS development.

Goldkuhl and Lyytinen (1982) were the first to introduce explicitly the idea of intersubjectivity in the context of user requirements. They saw IS development as a formalization of the professional language of the user community. One can also claim that the idea of a canonical conceptual schema includes an implicit idea of intersubjectivity. It is obvious that

(1996). This dimension describes the degree of agreement reached on the specification, ranging from a personal view to a common view. Pohl seems to interpret the dimension more as agreement between different stakeholders (systems analysts, manager, user, etc.), while Iivari and Hirschheim (1996) view intersubjectivity solely within the user community.

7 Many so-called user-centred methods are actually work-oriented rather than user-centred. 
intersubjectivity is gaining new relevance in the context of groupware and knowledge management systems. If an information system is to support a community of practice (Wegner, 1998), we should obviously base it on intersubjectively shared user (community) requirements. In the context of CSCW, Carstensein and Schmidt (1999) discuss 'classification schemes' as publicly visible and permanent pointers to items in the field of work. They point out that in large-scale settings actors cannot always ensure a consensus, implying that the classification scheme evolves in a process that is only partially concerted. Thus, they conclude that groupware systems should provide basic structures that one can use for establishing and maintaining conceptual structures, negotiate these, and still be open and flexible to local interpretations. This implies that we should view the user information requirements primarily as emergent, and that they may be only locally consistent.

\section{THE INFOLOGICAL EQUATION REVISITED}

\subsection{Introduction}

Every book on KM seems to start with its interpretation of concepts such as data, knowledge, and information. Much of this discussion suffers from very simplistic views, however. For example, Davenport and Prusak (1998) define data as a set of discrete, objective facts about events, Spiegler's (2000) definition of data echoes this view. Hammarberg (1981) discusses similar views, arguing that they are based on a foundationalist thesis that there exist raw, objective records of facts. He shows that this thesis fails. One reason is that we must always express data in a representational language of some kind, which provides the categories in terms of which we view the reality, implying that data are also "cooked" (cf. Hammarberg, 1981).

Tuomi (1999) points out that the generally accepted view in the KM community sees a hierarchy of data, information, and knowledge in which data are a prerequisite for information, and information is a prerequisite for knowledge (cf. also Spiegler, 2000). He criticizes this view and proposes a reversed hierarchy in which data emerge only after we have information, and that information emerges only after we already have knowledge. He points out that the world as an object of human knowing exists only as an interpreted world that is completely infused with meaning. Human cognition cannot see simple facts without these facts being part of its current meaning structure, and even the most elementary perception is already influenced by potential uses, expectations, context, and theoretical constructs. 
It is obvious that the above controversy echoes the discussion of the concepts of data, information, and knowledge within the Scandinavian infological tradition more than 20 years ago. The following section outlines how we can define these concepts within that tradition, applying Langefors' famous infological equation (Langefors, 1966; 1980).

First, applying Sundgren (1973), one can define data as follows: A datum is an arrangement of physical symbols according to some language to represent and communicate some idea. The physical symbols cover oral speech, written text, and computer representations. The represented idea may be a simple fact, a rule, or a complex piece of knowledge. It is just a historical "coincidence" that many of the traditional information systems processed data representing simple facts.

By the concept of information, I refer to the idea embedded in or conveyed by the data. The idea may be a simple fact or a complex piece of thought. The proposed definition allows a number of interpretations of the concept of information. Firstly, one can interpret the represented idea by the datum as information $\left(\mathrm{INF}_{\mathrm{S}}\right)$. A person interpreting the datum may capture the idea with greater or less accuracy, forming his own interpretation of it $\left(\mathrm{NFF}_{\mathrm{r} 1}\right)$. On the other hand, Mingers (1995) points out, referring to Dretske (1981) that a sign (data) carries all the information implied by the original idea. These consequences can be analytical (i.e. follow by definition), or nomic (based on scientific facts) or they may follow from the logic of the situation. Moreover, they may lead to expanded information on the part of the interpreter $\left(\mathrm{INF}_{\mathrm{r} 2}\right)$. Based on his/her pre-knowledge, the interpreter may also uncover hidden information in the datum, something that the original speaker or author really intended to convey, even though perhaps unconsciously (as exemplified by a psychoanalytical interpretation of a patient's stories), or something that (s)he said without intending to do so. These may provide the interpreter with additional information $\left(\mathrm{INF}_{\mathrm{r} 3}\right)$. Normally, at least in the case of a complex idea, $\mathrm{INF}_{\mathrm{r} 1} \neq \mathrm{INF}_{\mathrm{s}}$. If one takes a traditional transmission view of communication, we can interpret the difference caused by noise. On the other hand, the difference between $\mathrm{INF}_{\mathbf{S}}$ and $\mathrm{NF}_{\mathrm{ri}}$ opens a window for mutual learning and innovation, especially in the case of dialogue between a sender/speaker $s$ and a receiver/reader $r$.

What is knowledge? As is well known, philosophers have puzzled over this question for centuries without achieving a clear answer. If we confine ourselves to definitions that lie closer to KM, Bell (1976) defines knowledge as "a set of organized statements of facts or ideas, presenting a reasoned judgment or an experimental result transmitted to others through some communication medium or in some systematic form". Stehr (1992) characterizes knowledge as "capacity for action" and Nonaka and Takeuchi (1995) define it as "justified true belief." Based on these definitions a general characterization of knowledge could be: an organized set of reasonably 
justified ideas that increases one's capacity for action. The first characteristic "organized" implies that a collection of separate simple facts does not form knowledge. The second characteristic "justified" emphasizes that not all ideas constitute knowledge, but in order to be knowledge they must have some validity. For the sake of generality, I do not presuppose truthfulness to be the only criterion for validity. Actually, I interpret the third characteristic, that knowledge increases one's capacity for action, as a general criterion for a justified idea. I assume that action is the ultimate test of the validity of knowledge.

We can now analyze the relationship between knowledge, information, and data using the infological equation proposed by Langefors (1966).

\subsection{Articulation of the idea}

Langefors used his infological equation to describe the interpretation of data. In the following, I will first adopt the idea to describe the articulation of data (codification of the idea)

$$
\mathrm{D}\left(\mathrm{INF}_{\mathrm{s}}\right)=\mathrm{d}_{\mathrm{s}}\left(\mathrm{INF}_{\mathrm{s}}, \mathrm{K}_{\mathrm{s}}, \mathrm{t}\right) \text {. }
$$

$\mathrm{INF}_{\mathrm{S}}$ is the idea to be represented in data by the speaker/sender $\mathrm{s} . \mathrm{K}_{\mathrm{S}}$ is the knowledge of the speaker/sender, and $t$ is the time available to the speaker/sender for expressing his/her idea. $\mathrm{K}_{\mathrm{S}}$ covers all relevant knowledge that affects the speaker's/sender's capability to express his/her idea, such as knowledge of the topic (idea), knowledge of the potential reader(s)/receiver(s), knowledge of the potential use and context of use of the idea, and knowledge of the language and medium used.

\subsection{Interpretation of data}

We can model the interpretation directly using the infological equation of Langefors $(1966 ; 1980)$ :

$$
\mathrm{NNF}_{\mathrm{r}}=\mathrm{i}_{\mathrm{r}}\left(\mathrm{D}\left(\mathrm{NNF}_{\mathrm{s}}\right), \mathrm{K}_{\mathrm{r}}, \mathrm{t}\right) \text {. }
$$

This maintains that the information $\mathrm{INF}_{\mathrm{r}}$ acquired by the receiver/reader $\mathrm{r}$ by interpreting the data $D\left(I N F_{S}\right)$, representing an idea $\mathrm{INF}_{\mathrm{S}}$, is a function $\mathrm{i}_{\mathrm{r}}$ of the data $D\left(\mathrm{INF}_{\mathrm{S}}\right)$ to be interpreted, the pre-knowledge $\mathrm{K}_{\mathrm{r}}$ of the receiver/reader and the time $t$ available for the interpretation. The preknowledge $\mathrm{K}_{\mathrm{r}}$ covers all relevant knowledge that affects the receiver's/reader's ability to interpret the data $D\left(I N F_{S}\right)$. These include one's pre-knowledge of the idea that the speaker/sender wishes to communicate, knowledge of the potential speaker/sender, knowledge of the situation that articulated the data, including the time available for the articulation, knowledge of the language and medium used, and all the relevant analytical, nomic and social knowledge affecting the interpretation (Mingers, 1995). 


\subsection{Interpretation and articulation as "hermeneutic" processes}

The data (text) we interpret may be complex in terms of the idea $\mathrm{INF}_{\mathrm{s}}$. Its meaning is not necessarily revealed in a one-pass process of interpretation, but each successive reading of the data (text) may provide new insights, in the spirit of the hermeneutical spiral. Langefors (1980) suggests that this spiral can be modelled using the infological equation

$$
\mathrm{INF}_{\mathrm{r}}{ }^{\prime}=\mathrm{i}_{\mathrm{r}}\left(\mathrm{D}\left(\mathrm{INF}_{\mathrm{S}}\right), \mathrm{K}_{\mathrm{r}}{ }^{\prime}, t\right) \text {, }
$$

where $\mathrm{K}_{\mathrm{r}}{ }^{\prime}$ is the receiver/reader's knowledge after the first reading of the data $\mathrm{D}\left(\mathrm{INF}_{\mathrm{S}}\right)$, i.e.

$$
K_{r}{ }^{\prime}=K_{r}+i_{r}\left(D\left(I N F_{S}\right), K_{r}, t\right) .
$$

This process can continue as long as each new reading sheds new light on the interpreted data.

As a special case, the speaker/sender may serve as a reader/receiver of his/her earlier data (text). This may trigger revision of the earlier data (text); that is,

$$
\mathrm{D}\left(\mathrm{INF}_{\mathrm{S}}\right)^{\prime}=\mathrm{d}_{\mathrm{S}}\left(\mathrm{INF}_{\mathrm{S}}, \mathrm{K}_{\mathrm{s}}, \mathrm{t}^{\prime}\right),
$$

where $\mathrm{K}_{\mathrm{s}}$ ' is the sender's knowledge after reading his/her earlier text. That is,

$$
\mathrm{K}_{\mathrm{S}}{ }^{\prime}=\mathrm{K}_{\mathrm{S}}+\mathrm{i}_{\mathrm{S}}\left(\mathrm{D}\left(\mathrm{INF}_{\mathrm{S}}\right), \mathrm{K}_{\mathrm{S}}, \mathrm{t}\right) \text {. }
$$

\section{INFORMATION SYSTEMS DEVELOPMENT REVISITED}

We will look in this section at two recurrent trends in IS development:

- From in-house IS development to prefabricated IS development

- From heavy ISD methods to light ISD approaches

These trends are recurrent in the sense that they have popped up a number of times during the history of information systems.

\subsection{From in-house to prefabricated information systems development}

Adapting Gustafsson et al. (1982), one can interpret an information system as a computer-based system that provides its users with information on specified topics in a certain organizational context. This implies that an information system is specific to the organizational (or inter-organizational) context in which we implement it. Consequently, no prefabricated commercial software product is an information system as such. We cannot 
buy an information system, only the software (and hardware, and possibly data) to be used in its implementation.

Although much of our IS research has assumed in-house IS development, there have been recurrent instances of academic and business interest in prefabricated IS development under the labels of application packages in the 1980 's, ERP in the 1990's and COTS in the 2000's. The Scandinavian contribution to these movements seems to have been surprisingly thin, however, ${ }^{8}$ perhaps partly because of the relatively small number of major organizations in Scandinavia that have been interested in ERP. On the other hand, the majority of information systems implemented in Scandinavia have been based on application packages. ${ }^{9}$ This has especially been the case in small organizations, but it is nowadays increasingly common in large ones.

It is obvious that the predominance of prefabricated IS development will move the main emphasis of ISD onto the four (infological) problems discussed above. They are organizational alignment, requirements construction, organizational implementation, and IS evaluation.

\subsection{From heavy ISD methods to light ISD approaches}

Tensions between conceptualizations of the information systems and the ISD process models have driven our views of ISD. Function/processoriented methods such as SA/SD and ISAC dominated in the 1970s, to be replaced in the 1980s by data-oriented methods such as IE and NIAM. The 1990's saw the emergence of object-oriented methods such as OOA/OOD, OMT, and OOSA. These conceptualizations have tended to grow quite complex, as exemplified by UML (Booch et al., 1999). At the same time, lighter ISD process models have been proposed. Prototyping and evolutionary approaches made their appearance in the late 1970s, spiral models in the mid-1980s, and concurrent development in the 1990s, while agile methods emerged in the 2000s.

Having co-developed one ISD method during the 1980's, I have become more and more skeptical about the usefulness of these methods as such. It seems to me that they are often too complex as conceptual artifacts to be useful in practice. Without abstracting their essence, it is impossible to make sense of them. The concept of an ISD approach characterized by the

I know that the acquisition of application packages has been addressed in Finland by livari (1990a) and Saarinen and Vepsäläinen (1994), and that at least Nilsson (1991) and von Hellens (1991) have also worked on the topic at a Ph.D. dissertation level.

9 I do not have any definite statistics on this, but I would estimate that more than $90 \%$ of information systems, when measured in terms of the number of systems, are based on prefabricated application software. The often cited "horror" statistics of ISD failures tend to forget this majority of ISD development efforts. 
goals, guiding principles, major concepts, and principles of the ISD process (livari et al., 1998; 2000) attempts to provide an abstraction of this kind. I believe that ISD approaches are in line with agile "methods" in the sense that they are considerably lighter than specific methods.

One could consider agile "methods" to constitute a systems development approach. Abrahamson et al. (2002) provide a useful review of these, summarizing agility in four characteristics: incremental (small software releases with rapid cycles), cooperative (customer and developers working constantly together in close communication), straightforward (the method itself is easy to learn and modify) and adaptive (open to last moment changes). These features have much in common with the Scandinavian ISD approaches. The first characteristic is largely consistent with prototyping (Iivari, 1982; Bødker and Grønbæk, 1991). More explicitly, the PIOCO/OCIT method also allows fast incremental software development (Iivari, 1982; 1990a; 1990b), even though it does not specifically require it. The Trade Unionist approach has contributed to the cooperative aspects of systems development (Kensing and Munk-Madsen, 1993). Referring to the third characteristic, the PIOCO/OCIT method was explicitly developed with the idea of in-built flexibility so that it can easily be adapted not only to the characteristics of an organization or the specifics of a project but also to the daily contingencies of systems development (Iivari, 1989).

\section{CONCLUSIONS}

In summary, this essay proposes four distinctive ISD process knowledge areas for IS experts: organizational alignment, requirements construction, organizational implementation and IS evaluation. These correspond closely to the infological problems identified by Langefors (1977). Furthermore, increased prefabricated IS development will move the main emphasis of ISD towards these infological problems. In addition, to prefabricate IS development, a move may be perceive towards lighter ISD methods/approaches than are represented by current methods such as UML and RUP.

\section{REFERENCES}

Abrahamson, P., Salo, O., Ronkainen, J. and Warsta, J., Agile Software Development Methods, Review and Analysis, VTT Publications 478, Espoo, 2002

Barley, S.R., Technology as an occasion for structuring: Evidence from observations of CT scanners and the social order of radiology departments, Administrative Science Quarterly, 31, 1996, pp. 78-101 
Bell, D., The Coming of Post-Industrial Society: A Venture of Social Forecasting, Basic Books, New York, Basic Books, New York, 1976 (First published, 1973)

Beyer, H. and Holtzblatt, K., Contextual Design, Defining Customer-Centered Systems, Morgan Kaufmann Publishers, Inc. San Fransisco, 1998

Booch, G., Rumbaugh, J. and Jacobson, I., The Unified Modeling Language User Guide, Addison Wesley, Reading, MA, 1999

Brusilovsky, P., Methods and techniques of adaptive hypermedia, User Modeling and User Adapted Interaction, 6(2-3), 1996, pp. 87-129

Bubenko, J.A. Jr., Information modeling in the context of system development, Lavington, S. (ed.), Information Processing 80, North-Holland, Amsterdam, 1980, pp. 395-411

Bødker, S. and Grønbæk, K., Cooperative prototyping studies - users and designers envision a dental case record system. in Bowers, J.M. and Benford, S.D. (eds.). Studies in Compute Supported Cooperative Work. Elsevier Science Publishers B.V. (North-Holland), Amsterdam, 1991, 315-332

Carstensen, P.H. and Schmidt, K., Computer supported cooperative work: New challenges to systems design, in Itoh, K. (ed), Handbook of Human Factors, Tokyo, 1999

Davenport, T.H. and Prusak, L., Working Knowledge, Harward Business School Press, Boston, Massachusetts, 1998

Dretske, F., Knowledge and the Flow of Information, Basil Blackwell, Oxford, 1981

Ehn, P., Work-Oriented Design of Computer Artifacts, Arbetslivscentrum, Stockholm, 1988

Flynn, D.J. and Jazi, M.D., Constructing user requirements: a social process for a social context, Information Systems Journal, 8(1), 1998, pp. 53-82

Goldkuhl, G. and Lyytinen, K., A language action view of information systems, in Ross, C. and Ginzberg, M. (eds.): Proceedings of the Third Conference on Information Systems, Ann Arbor, Michigan, 1982, pp. 13-29

Gustafsson, M.R., Karlsson, T. and Bubenko, J. Jr., A declarative approach to conceptual information modeling, in Olle, T.W., Sol, H.G. and Verrijn-Stuart, A.A. (eds.): Information systems design methodologies: a comparative review, North-Holland, Amsterdam, 1982, pp. 93-142

Hammarberg, R., The cooked and the raw, Journal of Information Science, Vol. 3, No. 6, 1981, pp. 261-267

Hammer, M. and Champy, J., Reengineering the Corporation, A Manifesto for Business Revolution, Nichola Brealey, London, 1994

Henfridsson, O., Holmström, J. and Söderholm, A., Why are organizational theories so rarely used in Scandinavian IS research, Scandinavian Journal of Information Systems, 9(2), 1997, pp. 53-56

Iivari, J., Taxonomy of the experimental and evolutionary approaches to systemeering, in Hawgood, J. (ed.), Evolutionary Information Systems, North-Holland, Amsterdam, 1982, pp. 101-119

Iivari, J., A methodology for IS development as organizational change: A pragmatic contingency approach, in Klein, H.K. and Kumar, K. (eds.), Systems Development for Human Progress, North-Holland, Amsterdam, 1989, pp. 197-217

Iivari, J., Implementability of in-house developed vs. application package based information systems, Data Base, 21(1), 1990a, pp. 1-10

Iivari J., Hierarchical spiral model for information system and software development, Part 1: theoretical background, Information and Software Technology, 32(6), 1990b, pp. 386-399

Iivari J., Hierarchical spiral model for information system and software development, Part 2: design process, Information and Software Technology, 32(7), 1990c, pp. 450-458

Iivari, J., The organizational fit of information systems, Journal of Information Systems, 2(1), 1992, pp. 3-29 
Iivari, J. and Hirschheim, R., Analyzing information systems development: A comparison and analysis of eight IS development approaches, Information Systems, 21(7), 1996, pp. 551575

Iivari, J., Hirschheim, R. and Klein. H.K., A paradigmatic analysis contrasting information systems development approaches and methodologies, Information Systems Research, 9(2), 1998, pp. 164-193

livari, J., Hirschheim, R. and Klein, H.K., A dynamic framework for classifying information systems development methodologies and approaches, Journal of Management Information Systems, Vol. 17, No. 3, 2000-2001 pp. 179-218

livari, J., Hirschheim, R. and Klein, H.K., Towards more professional information systems development: ISD as knowledge work, ECIS'2001, Bled Slovenia, 2001

Iivari, J. and Kerola, P., A sociocybernetic framework for the feature analysis of information systems design methodologies, in Olle, T.W., Sol, H.G. and Tully, C.J. (eds.), Information systems design methodologies: a feature analysis, North-Holland, Amsterdam, 1983, pp. $87-139$

Iivari, J. and Koskela, E., Choice and quality criteria for data system selection, in Samet, P.A. (ed.), Proceedings of EurolFIP 79, European Conference on Applied Information Technology, North-Holland, Amsterdam, 1979, pp. 143-150

Iivari, J. and Koskela, E., The PIOCO model for IS design, MIS Quarterly, Vol. 11, No. 3, 1987, pp. 401-419

livari, J. and Linger, H., Knowledge Work as Collaborative Work: A Situated Activity Theory View, Proceedings of the 32nd Hawaii International Conference on System Sciences, 1999

Jacobson, I., Christerson, M., Jonsson, P. and Övergaard, G., Object-Oriented Software Engineering, A use case driven approach, Addison Wesley, Wokingham, England, 1992

Karsten, H., Weaving Tapestry: Collaborative Information Technology and Organisational Change, Jyväskylä University Press, Jyväskylä, 2000

Kensing. F. and Munk-Madsen, A., PD: Structure in the toolbox, Communications of the $A C M, 36(4), 1993$, pp. 78-85

Kerola, P. and Järvinen, P., Systemointi II (Systemeering II), Oy Gaudeamus Ab, Helsinki, 1975

Kling, R and Scacchi, W., Computing as social action: The social dynamics of computing in complex organizations, in Yovits, M.C. (ed.). Advances in Computers. 19, 1980, 249-327

Kling, R and Scacchi, W., The web of computing: Computer technology as social organization, in Yovits, M.C. (ed.). Advances in Computers. 21, 1982, pp. 1-90

Kuutti, K., Activity theory and its applications in information systems research and design, Nissen, H.-E., Klein, H.K. and Hirschheim, R., (eds.), Information Systems Research Arena for the 90's, North-Holland, Amsterdam, 1991, pp. 529-550

Langefors, B., Theoretical Analysis of Information Systems, Studentlitteratur, Lund, Sweden, 1966

Langefors, B., Information systems theory, Information Systems, 2, 1977, pp. 207-219

Langefors, B., Infological models and information user views, Information Systems, 5, 1980, pp. 17-32

Langley, A., Minzberg, H., Pitcher, P., Posada, E. and Saint-Macary, J., Opening up decision making: The view from the black stool, Organization Science, 6(3), 1995, pp. 260-279

Lundeberg, M., Goldkuhl, G. and Nilsson, A., Systemering, Studentlitteratur, Lund, 1978

Lundeberg, M., Goldkuhl, G. and Nilsson, A., Information Systems Development: A systematic approach, Prentice-Hall, Englewood Cliffs, New Jersey, 1981 
Majchrzak, A., Rice, R.E., Malhotra, A., King, N. and Ba, S., Technology adaptation: The case of a computer-supported inter-organizational virtual tem, MIS Quarterly, 24(4), 2000, pp. $569-600$

Miles, R.E. and Snow, C.C., Causes of failures in network organizations, California Management Review, 34(4), 1992, pp. 53-72

Mingers, J.C., Information and meaning: foundations for an intersubjective account, Information Systemes Journal, 5, 1995, pp. 285-306

Minzberg, H., The Rise and Fall of Strategic Planning, Prentice Hall, 1994

Nilsson, A.G., Anskaffning av standardsystem för att utveckla verksamheter, Utveckling och prövning av SIV-metoden, Ph.D. Diss., Stockholm Handelshögskolan, Stockholm, 1991

Nonaka, I. and Takeuchi, H., The Knowledge Creating Company, Oxford University Press, New York, 1995

Pohl, K., The three dimensions of requirements engineering: A framework and its applications. Information Systems. 19(3), 1994, pp. 243-258

Porra, J., Colonial Systems, Information Colonies and Punctuated Prototyping, Jyväskylä Studies in Computer Science, Economics and Statistics 33, University of Jyväskylä, Jyväskylä, 1996

Powell, W., Neither market nor hierarchy: network forms of organization, Research in Organizational Behavior, 12, 1990, pp. 295-336

Saarinen, T. and Vepsalainen, A.P.J., Procurement strategies for information systems, Journal of Management Information Systems, 11(2), 1994, pp. 187-208

Schmidt, K., The problem with "awareness", Introductory remarks on 'awareness in CSCW', Computer Supported Cooperative Work, 11, 2002, pp. 285-298

Schmidt, K. and Bannon, L., Taking CSCW seriously: Supporting articulation work, Computer Supported Cooperative Work, 1(1-2), 1992, pp. 7-40

Schmidt, K. and Simone, C., Coordination mechanisms: Towards a conceptual foundation of CSCW system design, Computer Supported Cooperative Work, 5(2-3), 1996, pp. 155-200

Simon, H., The New Science of Managerial Decision, Harper and Row, 1960

Smith, H.A. and McKeen, J.D., Developments in practice VIII: Enterprise content management, Communications of the Association of Information Systems, Vol. 11, 2003, pp. 647-659

Spiegler, I., Knowledge Management: A new idea or a recycled concept?, Communications of the Association for Information Systems, Vol. 3, Article 14, June 2000

Spinuzzi, C., A Scandinavian challenge, a US response: Methodological assumptions in Scandinavian and US prototyping approaches, SIGDOC'02, Toronto, Ontario, Canada, 2002, pp. 208-215

Stehr, N., Experts, counselors and advisers, in Stehr, N. and Ericsson, R.V. (eds.), The Culture and Power of Knowledge, Walter de Gruyter, Berlin, 1992, pp. 107-155

Sundgren, B., An Infological Approach to Data Bases, Skriftserie utgiven av statistiska centralbyrån, Nummer 7, Statistiska Centralbyrån, Stockholm, 1973

Tuomi, I., Data is more than knowledge, Implications of the reversed knowledge hierarchy for knowledge management and organizational memory, Journal of Management Information Systems, 16(3), 2000, pp. 103-117

von Hellens, L.A., Conditions for Success in the Design and Implementation of Packaged Software. A Study of Accounting Software for Small Companies in the United Kingdom, Publications of The Turku School of Economics and Business Administration, Series A-3, Turku, 1991.

Weill. P. and Vitale, M.R., Place to Space: Migrating to eBusiness Models, Harvard Business School Press, Harvard, MA 2001 
Wenger, E., Communities of Practice: Learning, Meaning and Identity, Cambridge University Press, Cambridge, 1998 